\title{
The Expression of the Human Cathelicidin LL-37 in the Human Dental Pulp: An In vivo Study
}

\author{
Bernardo F. Sarmiento ${ }^{1}$ Anita Aminoshariae ${ }^{2 *}$, Mohammed Bakkar $^{2}$, Tracey Bonfield ${ }^{3}$, \\ Santosh Ghosh ${ }^{4}$, Thomas A Montagnese ${ }^{5}$ and Andre K Mickel ${ }^{5}$ \\ ${ }^{1}$ Department of Graduate Endodontics, Case Western Reserve University School of Dental Medicine \\ ${ }^{2}$ Department of Endodontics, Case School of Dental Medicine \\ ${ }^{3}$ Division of Pediatric Pulmonology, Allergy \& Immunology, Case School of Medicine \\ ${ }^{4}$ Department of Biological Sciences, Case School of Dental Medicine \\ ${ }^{5}$ Diplomate, American Board of Endodontics, Case School of Dental Medicine
}

Received: May 24, 2016; Accepted: June 09, 2016; Published: July 01, 2016

*Corresponding author: Anita Aminoshariae, Director, Predoctoral Endodontics, Department of Endodontics, Diplomate of American Board of Endodontics, 2124,cornell Rd., DOA280, Cleveland, Ohio 44106, United States; Tel no: 001(216) 368-1188; E-mail: Axa53@case.edu

\begin{abstract}
Introduction: LL37 is an antimicrobial peptide and the only member of Cathelicidin family found in humans. Thus, the purpose of this study was to identify the expression of LL37 in the normal and inflamed dental pulp.

Materials and Methods: Ten teeth diagnosed as symptomatic irreversible pulpitis with symptomatic apical periodontitis and six teeth as normal pulp with normal apical tissues undergoing nonsurgical root canal treatment meeting the inclusion criteria were selected in this in vivo study. Blood samples were collected from the pulp chamber upon initial exposure, and transferred into Eppendorf tubes containing Phosphate Buffered Saline (PBS) solution. Samples were processed using the BCA (Bicinchoninic acid) Protein Assay and LL37 levels were measured by Enzyme Linked Immunosorbent Assay (ELISA). Data were analyzed using Graphpad Prism and SPSS software.
\end{abstract}

Results: $16.7 \%$ and $80 \%$ of samples in the normal pulp and symptomatic irreversible pulpitis group expressed LL37, respectively. There was a significantly higher expression of LL37 in the inflamed pulp ( $p=0.03)$.

Conclusions: Inflammation may induce the expression of LL37 in the human dental pulp. These findings suggest that LL37 may play a role in the innate immunity. Further studies are needed to quantify the levels of LL37 expression.

Keywords: LL-37; Antimicrobial peptides; Cathelicidin; Expression; Dental pulp; Inflammation

\section{Introduction}

The human dental pulp is exposed to a variety of biologic, chemical, and physical stimuli during caries development and dental therapy demonstrating a wide range of responses, including defense and repair processes [1]. The dental pulp is equipped to mount an innate and adaptive response in order to defend itself [2]. Although the mechanism of the host defense against microbial invasion in the human dental pulp is not fully understood, certain host defense systems have been identified to be involved in the innate response upon the eliciting of an attack to the human dental pulp, consisting of receptors that are structured to recognize unique microbial components and effectors that can rapidly respond to the assaults; these effectors are known as Antimicrobial Peptides [3,4]. Various families of antimicrobial peptides have been identified in the oral cavity including the Cathelicidins and Defensins [5].

To date, the antimicrobial peptide LL37 is the only cathelicidin found in humans [6]. It is formed from the last 37 amino acid residues of the C-terminus of human Cationic Antimicrobial Peptide 18 (hCAP18) [7].

LL-37 is amphipathic, helical peptide found throughout the body and being expressed in epithelial layers of the skin, saliva, and junctional epithelium of the gingiva [8] bone and bone marrow [9]. LL37 has been shown to exhibit a broad spectrum of antimicrobial activity [10] against bacteria, fungi, and viruses [11], and inhibits lipopolysaccharide bioactivity [12]. In addition to its antimicrobial properties LL37 induces the migration of monocytes, T cells, and keratinocytes [13]; inhibits the increase in cytokine production induced by lipopolysaccharide in dendritic cells [14]; and induces angiogenesis [15]. Furthermore, LL37 has antimicrobial activity against cariogenic and periodontopathogenic bacteria [16]. LL37 plays a central role in innate immune responses and inflammation [17]. To date there has not been an in vivo study that has detected the expression of LL37 directly in the human dental pulp.

Thus, the purpose of this study was to identify the expression of LL37 in the normal and inflamed dental pulp diagnosed as symptomatic irreversible pulpitis with symptomatic apical periodontitis.

\section{Materials and Methods}

\section{Patient Selection}

Patients that underwent Non-Surgical Root Canal Treatment 
from Case Western Reserve University, Cleveland, OhioGraduate Endodontics program were randomly selected from August 2014 - October 2014 to participate in this study. The treatment plans from any of the patients remained without any modification during this investigation. Patients were given a written description of the study; approval and informed consent were obtained. The Institutional Review Board (IRB) approval was granted. Patients selected in this study were included with the following diagnosis: symptomatic irreversible pulpitis with symptomatic apical periodontitis, and for the control group, samples were processed from teeth with normal pulp with normal apical tissues from teeth requiring prophylactic endodontic treatment. The inclusion criteria are the following: American Society of Anesthesiologists (ASA) physical status 1, no history of known allergies, non-smokers, age between eighteen and sixty-five, healthy periodontal status and restorable teeth. Exclusion criteria: patient on antibiotics, patients with any known allergies, pregnancy, diabetes, immunocompromised patients, any periodontal probing depth greater than $5 \mathrm{~mm}$ or teeth with a furcation or trifurcation involvement, teeth diagnosed with a necrotic pulp, previously initiated endodontic treatment and/or previously endodontically treated teeth.

Each patient's pulpal and periradicular status was evaluated

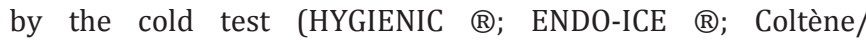
Whaledent Inc., Cuyahoga Falls, OH, USA) and electric pulp test (EPT) (Vitality Scanner; SybronEndo, Orange, CA, USA) to assess pulp vitality. Percussion, palpation, mobility and periodontal examinations were performed. Digital periapical and bitewing radiographs of the tooth in question (Planmeca ${ }^{\circledR}$ ProSensor ${ }^{\mathrm{TM}}$; PLANMECA USA, Inc., Roselle, IL, USA) were obtained.

The following type of patients was subsequently included: samples collected from 10 teeth of patients diagnosed with Symptomatic Irreversible Pulpitis (SIP) and Symptomatic Apical Periodontitis (SAP). As a negative control, samples were also taken from 6 teeth diagnosed as having normal pulp which had no clinical or radiographic evidence of, pulpal and periapical pathosis but needed routine endodontic treatment for prosthodontic reasons. The definition of the SIP SAP is described in a previous study [18]. Briefly, the clinical characteristics of the cases included subjective and objective findings that are described:

Symptomatic Irreversible Pulpitis (SIP): Included sharp pain upon thermal stimulus, lingering pain (often 30 seconds or longer after stimulus removal).

Symptomatic Apical Periodontitis (SAP): Pain to percussion and/or palpation.

\section{Control}

Normal pulp with normal apical tissues, where the teeth indicated absence of caries, symptoms, cracks and restorations.

\section{Operative Procedure \& Site Selection}

The sampling procedure is as described by Martinho, et al. [19]. After local anesthesia and absolute isolation with the rubber dam, an access opening was made into the pulp chamber using a sterile size \#2 round carbide bur (DENTSPLY Maillefer, Tulsa, $\mathrm{OK}$ ) friction grip in a dental high speed hand piece. A safe ended (Endo-Z bur) (DENTSPLY Maillefer, Tulsa, OK) was used to deroof the pulp chamber. Hemorrhage and tooth structure remnants were controlled, and removed using a saline irrigating solution. Standard size \#30 sterile paper points (Lexicon®; DENTSPLY Tulsa Dental Specialties, John City, TN, USA) were introduced into the canal orifice remaining for 30 seconds for the blood sample absorption. Thereafter, the paper points were transferred into Eppendorf tubes (Eppendorf Tubes $\AA$, Lakewood, OH, USA) containing $400 \mu \mathrm{L}$ of phosphate-buffered saline (PBS) (Gibco ${ }^{\circledR}$ PBS, Grand Island, NY, USA) at pH 7.4, centrifuged at $1500 \mathrm{xg}$ at $4 \mathrm{C}^{\circ}$ for 15 minutes and stored in a freezer compartment at $-70^{\circ} \mathrm{C}$ until use.

\section{Bicinchoninic acid assay (BCA)}

Bicinchoninic acid assay was first introduced by Smith, et al. [20] and is a sensitive methodology for protein quantification [21]. The BCA protein assay (Pierce, Rockford, IL, USA) measured the total concentration of protein in the samples according to manufactures instructions.

\section{Measurement by Enzyme-linked Immunosorbent Assay (ELISA)}

LL37 levels in the paper points were measured using ELISA assay (Hycult Biotech Inc.®; Plymouth Meeting, PA, USA). LL37 was detected at from a range of $0.1 \mathrm{ng} / \mathrm{ml}$ to $100 \mathrm{ng} /$ $\mathrm{ml}$. The working volume of $100 \mu \mathrm{l} /$ well was the standard for the dilution. The human LL-37 ELISA a solid-phase enzymelinked Immunosorbent assay based on the sandwich principle was performed. Micro titer wells were coated with antibody to recognize the human LL-37, a total $(100 \mu \mathrm{L})$ of the sample was added to each well and the plates were incubated for $60 \mathrm{~min}$. at $20-25^{\circ} \mathrm{C}$ the samples were washed four times, thereafter a Biotinylated tracer antibody $(100 \mu \mathrm{l})$ was added to bind and capture the peptide and incubated for $60 \mathrm{~min}$. at $20-25^{\circ} \mathrm{C}$ the samples are washed four times. Streptavidin-peroxidase conjugate $(100 \mu \mathrm{l})$ was added to bind to the tracer; the samples were again washed four times. A substrate was added Tetra Methylbenzidine (TM solution) $(100 \mu \mathrm{l})$ to react with the conjugate incubated for $30 \mathrm{~min}$ at $20-25^{\circ} \mathrm{C}$. Finally, the enzyme reaction was stopped by the addition $(100 \mu \mathrm{l})$ of oxalic acid stop solution and immediate readings of the plates at $450 \mathrm{~nm}$ measurements of absorbance are done with the spectrophotometer.

\section{Statistical Analyses}

Mann-Whitney test was used to compare the protein expression levels (BCA) and LL-37 levels between normal pulp and symptomatic irreversible pulpitis. The level of significance was set at $P$-value $=0.05$ with a post Dunn test. Data was analyzed by using Graphpad Prism and SPSS 22 software (IBM SPSS Statistics for Windows, Version 22.0. Armonk, NY).

\section{Results}

In this study there were a total of sixteen teeth (normal pulp 
$\mathrm{n}=6$, symptomatic irreversible pulpitis with symptomatic apical periodontitis $\mathrm{n}=10$ ). Table details the patient age and gender, and data distribution.

\section{BCA Levels}

The mean total protein concentration for the normal pulp was $884.4 \pm 466.4 \mathrm{mg} / \mathrm{ml}$ and symptomatic irreversible pulpitis was $786.6 \pm 463 \mathrm{mg} / \mathrm{ml}$. There was no statistical significance difference in protein levels between normal pulp and symptomatic irreversible pulpitis ( $p=0.79$ ) Figure 1 .

\section{LL37 Levels}

LL37 were detected only in one sample out of 6 normal pulps, however in symptomatic irreversible pulpitis with symptomatic apical periodontitis (SIP SAP) samples, LL37 were detected in 8 out of 10 samples. The mean pulpal concentration of LL-37 in normal pulps $0.2 \pm 0.6 \mathrm{ng} / \mathrm{ml}$ and symptomatic irreversible pulpitis $1.5 \pm 1.2 \mathrm{ng} / \mathrm{ml}$. The levels of LL37 with symptomatic irreversible pulpitis are significantly higher than normal pulp ( $p$ $=0.03$ ) Figure 2 .

\section{Discussion}

To the best of our knowledge this is the first study to report on the expression of LL-37 directly in the human dental pulp. A previous study by Kajiya, et al. [22] had hypothesized that LL37 could be expressed in the human dental pulp due to presence of neutrophil infiltration which produces LL37, and could be expressed in inflamed pulp tissues. Based on the results of the present study LL37 expression of the SIP SAP group was statistically significant compared to the group with normal pulp implicating that there are differences upon the upregulation of LL37 between the healthy and inflamed pulp tissue.
The importance of LL37 among its diverse biological effects is the contributable role it plays in maintaining micro biota-host homeostasis and promoting repair responses to inflammatory insults [9]. The current trend in the endodontic literature is the focus on the ability of LL37 to induce human pulp cell migration which is an attributing factor in the regeneration of the pulpdentin complex for the formation of reparative dentin commonly known as Dentin Bridging [22]. Aforementioned, among other characteristics of LL37 its angiogenic effect is being widely observed as potential novel therapeutic agent in the medical field [15]. In the field of Endodontics the potential use of LL37 as a pulp-capping agent for the reversible healing of the inflamed dental pulp is being contemplated for a promising clinical use [23].

It has been reported that levels of total protein in the Gingival Crevicular Fluid (GCF) of diseased teeth with apical periodontitis were higher than contralateral healthy teeth in the same patient [24]. However, in our study the total protein concentration levels were not statistically significant between normal and inflamed dental pulp, $p=0.79$ Figure 1 . Due to the nature of the study obtaining SIP and normal pulp from the same patient were inapplicable.

Enzyme-linked ImmunoSorbent Assay (ELISA) was used to evaluate human pulpal blood with respect to LL37 levels collected by paper points. Nakanishi, et al [25] used ELISA to analyze human pulpal blood samples collected by nylon pellets and found that IgG, IgA, IgM, elastase, and especially prostaglandin E2, but not IL-1, IL- 6 or TNF- $\alpha$, were elevated in inflamed compared to healthy teeth. Another study found significantly higher levels $(P<0.05)$ of IL-6, IL-8, IL-10, TNF- $\alpha$ and IFN- $\gamma$ were detected in irreversible pulpitis as compared to normal pulp using ELISA and samples were collected by sterile cotton pellets [26].

Table 1: Demographic characteristics and endodontic diagnosis of the healthy patients UD: undetected; N/A: not available data.

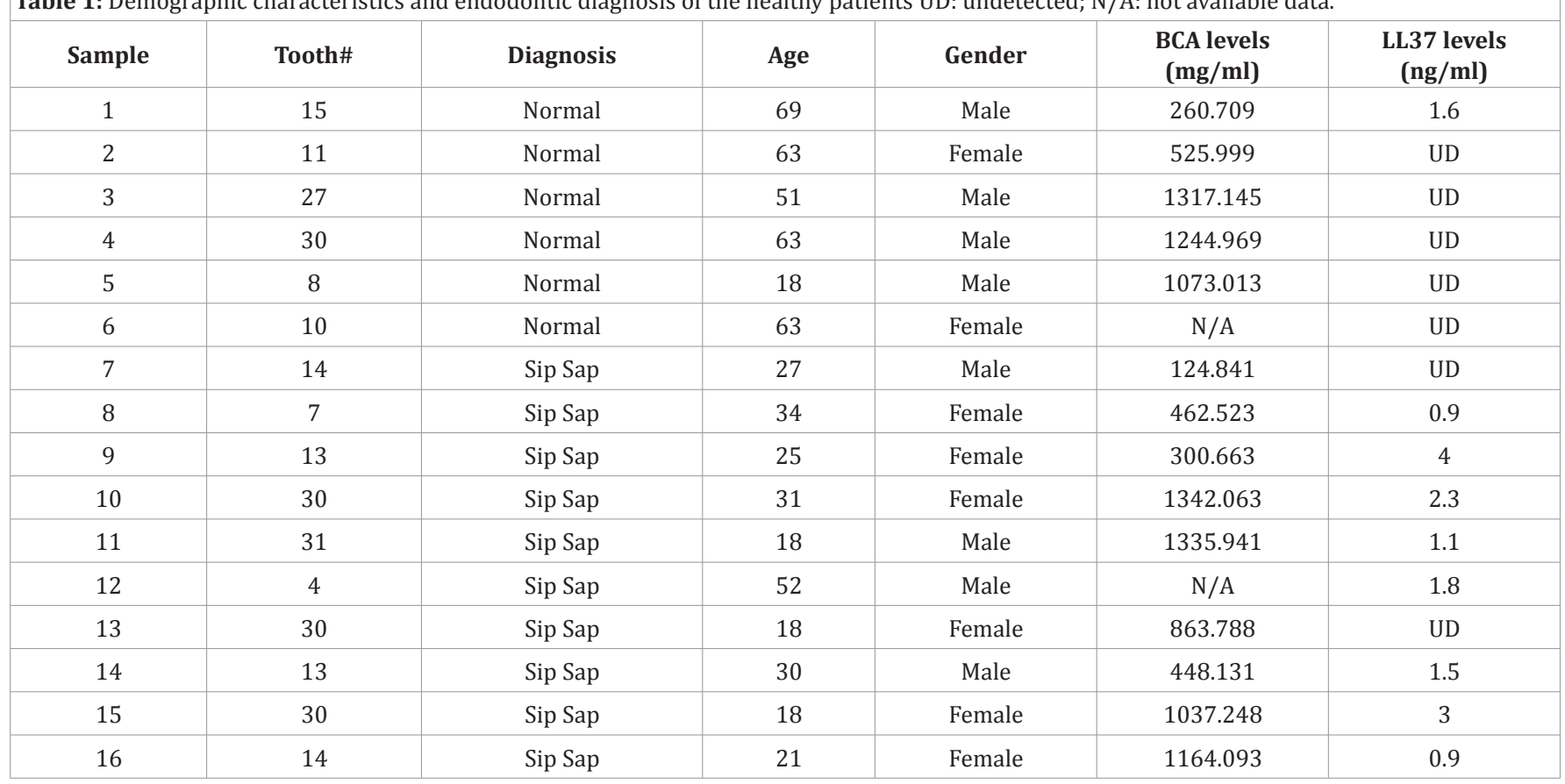




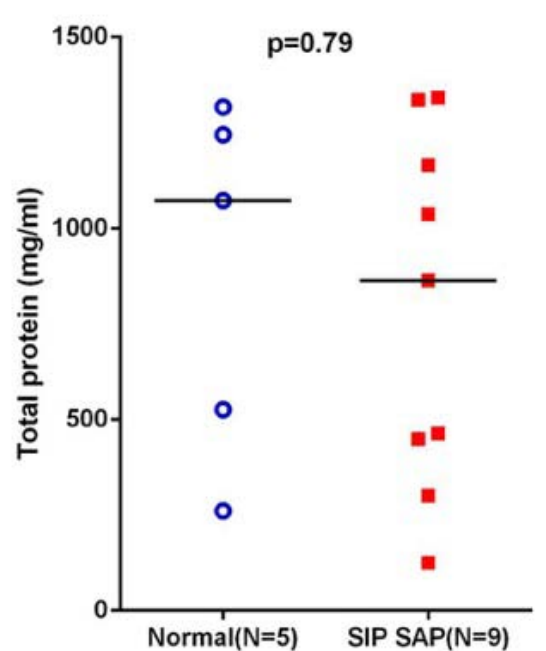

Figure 1: Bicinchoninic Acid Assay (BCA) to determine the total protein levels $(\mathrm{mg} / \mathrm{ml})$ between normal pulp with normal apical tissues and Symptomatic Irreversible Pulpitis (SIP) with Symptomatic Apical Periodontitis (SAP). No statistical significant difference $(p=0.79)$, MannWhitney test.

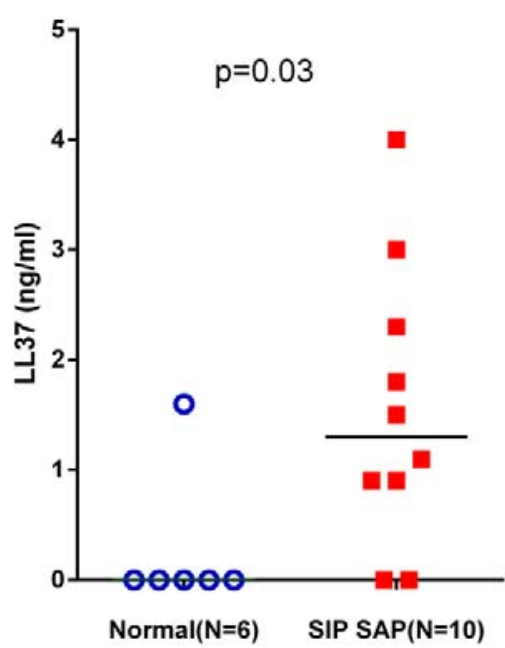

Figure 2: Enzyme-linked Immunosorbent Assay (ELISA) to determine the LL37 levels $(\mathrm{ng} / \mathrm{ml})$ in normal pulp with normal apical tissues and symptomatic irreversible pulpitis with symptomatic apical periodontitis. Statistically significant ( $\mathrm{p}=0.03$ ), Mann-Whitney test with post-Dunn test.

The limitation of our study was the sample size, as it was very difficult to obtain higher amount of samples and equal distribution among both groups especially in the control group, where obtaining normal pulp samples from teeth undergoing root canal therapy for prosthodontic considerations are very limited and/or impossible to acquire. Pulpal tissue vascularization provenience is difficult to determine in hyperemic dental pulp tissues as with the endodontic clinical testing we are only able to diagnose based on subjective and objective findings [27]. This perhaps might dictate the result in the normal pulp group in which expression of
LL37 was detected in one sample only consequently of a potential misdiagnosis; as an accurate diagnosis of different pulpal inflammation forms is only possible by using histopathologic or molecular biologic techniques [28].

In conclusion, based on the results of the present study it is acknowledged that inflammation induces the expression of LL37 [13] in the human dental pulp; these findings suggest that LL37 plays a role in the innate immunity [29]. Further research is needed to better quantify expression levels of LL37 as well as detect the degree of inflammation which might up regulate LL37 in human dental pulps.

\section{References}

1. Hahn CL, Liewehr FR. Innate immune responses of the dental pulp to caries. J Endod. 2007;33(6):643-651.

2. Hahn CL, Liewehr FR. Relationships between caries bacteria, host responses, and clinical signs and symptoms of pulpitis. J Endod. 2007;33(3):213-219.

3. Zasloff M. Antimicrobial peptides, innate immunity, and the normally sterile urinary tract. Journal of the American Society of Nephrology: JASN. 2007;18(11):2810-2816.

4. Peters BM, Jabra-Rizk MA, Mark E Shirtliff. Antimicrobial Peptides: Primeval Molecules or Future Drugs? PLoS Pathog. 2010;6(10):e1001067.

5. Murakami M, Ohtake T, Dorschner RA, Gallo RL. Cathelicidin antimicrobial peptides are expressed in salivary glands and saliva. J Dent Res. 2002;81(12):845-850.

6. Dürr UH, Sudheendra U, Ramamoorthy A. LL-37, the only human member of the cathelicidin family of antimicrobial peptides. Biochimica et Biophysica Acta (BBA)-Biomembranes. 2006;1758(9):1408-1425.

7. Sorensen OE, Follin P, Johnsen AH, Calafat J, Tjabringa GS, Hiemstra PS, et al. Human cathelicidin, hCAP-18, is processed to the antimicrobial peptide LL-37 by extracellular cleavage with proteinase 3. Blood. 2001;97(12):3951-3959.

8. Dale BA. Periodontal epithelium: a newly recognized role in health and disease. Periodonto 2000. 2002;30(1):70-78.

9. Nakamichi Y, Horibe K, Takahashi N, Udagawa N. Roles of cathelicidins in inflammation and bone loss. Odontology. 2014;102(2):137-146.

10. Durr UH, Sudheendra US, Ramamoorthy A. LL-37, the only human member of the cathelicidin family of antimicrobial peptides. Biochim Biophys Acta. 2006;1758(9):1408-1425.

11. Niyonsaba F, Ogawa H. Protective roles of the skin against infection: implication of naturally occurring human antimicrobial agents $\beta$-defensins, cathelicidin LL-37 and lysozyme. J Dermatol Sci. 2005;40(3):157-168.

12. Ciornei CD, Sigurdardóttir T, Schmidtchen A, Bodelsson M. Antimicrobial and chemoattractant activity, lipopolysaccharide neutralization, cytotoxicity, and inhibition by serum of analogs of human cathelicidin LL-37. Antimicrob Agents Chemother. 2005;49(7):2845-2850

13. Agerberth B, Charo J, Werr J, Olsson B, Idali F, Lindbom L, et al. The human antimicrobial and chemotactic peptides LL-37 and $\alpha$-defensins are expressed by specific lymphocyte and monocyte populations. Blood. 2000;96(9):3086-3093.

14. Davidson DJ, Currie AJ, Reid GS, Bowdish DM, MacDonald KL, Ma RC, 
et al. The cationic antimicrobial peptide LL-37 modulates dendritic cell differentiation and dendritic cell-induced $\mathrm{T}$ cell polarization. The Immunol. 2004;172(2):1146-1156.

15. Koczulla R, von Degenfeld G, Kupatt C, Krötz F, Zahler S, Gloe T, et al An angiogenic role for the human peptide antibiotic LL-37/hCAP-18. Journal of Clinical Investigation. 2003;111(11):1665.

16. Ouhara K, Komatsuzawa H, Yamada S, Shiba H, Fujiwara T, Ohara $\mathrm{M}$, et al. Susceptibilities of periodontopathogenic and cariogenic bacteria to antibacterial peptides, $\beta$-defensins and LL37, produced by human epithelial cells. Journal of Antimicrobial Chemotherapy. 2005;55(6):888-896.

17. Ramos R, Silva JP, Rodrigues AC, Costa R, Guardao L, Schmitt F, et al. Wound healing activity of the human antimicrobial peptide LL37. Peptides. 2011;32(7):1469-1476.

18. Levin LG, Law AS, Holland GR, Abbott PV, Roda RS. Identify and define all diagnostic terms for pulpal health and disease states. J Endod. 2009;35(12):1645-1657

19. Martinho FC, Gomes BP. Quantification of endotoxins and cultivable bacteria in root canal infection before and after chemomechanical preparation with 2.5\% sodium hypochlorite. J Endod. 2008;34(3):268272.

20. Smith P, Krohn RI, Hermanson G, Mallia A, Gartner F, Provenzano M, et al. Measurement of protein using bicinchoninic acid. Anal biochem. 1985;150(1):76-85.

21. Walker JM. The bicinchoninic acid (BCA) assay for protein quantitation. The Protein Protocols Handbook: Springer; 2009. p. 11-15.
22. Kajiya M, Shiba H, Komatsuzawa H, Ouhara K, Fujita T, Takeda K, et al. The antimicrobial peptide LL37 induces the migration of human pulp cells: a possible adjunct for regenerative endodontics. J Endod. 2010;36(6):1009-1013

23. Khung R, Shiba H, Kajiya M, Kittaka M, Ouhara K, Takeda K, et al. LL37 induces VEGF expression in dental pulp cells through ERK signalling. Int Endod J. 2015;48(7):678-679.

24. Burgener B, Ford AR, Situ H, Fayad MI, Hao JJ, Wenckus CS, et al. Biologic markers for odontogenic periradicular periodontitis. J Endod. 2010;36(8):1307-1310.

25. Nakanishi T, Matsuo T, Ebisu S. Quantitative analysis of immunoglobulins and inflammatory factors in human pulpal blood from exposed pulps. Journal of endodontics. 1995;21(3):131-136.

26. Elsalhy M, Azizieh F, Raghupathy R. Cytokines as diagnostic markers of pulpal inflammation. Int Endod J. 2013;46(6):573-580.

27. Newton CW, Hoen MM, Goodis HE, Johnson BR, McClanahan SB. Identify and determine the metrics, hierarchy, and predictive value of all the parameters and/or methods used during endodontic diagnosis. J Endod. 2009;35(12):1635-1644.

28. Paris S, Wolgin M, Kielbassa AM, Pries A, Zakrzewicz A. Gene expression of human beta-defensins in healthy and inflamed human dental pulps. J Endod. 2009;35(4):520-523.

29. Ganz T. The role of antimicrobial peptides in innate immunity. Integrative and comparative biology. 2003;43(2):300-304. 